\title{
Prolongation of acid-fast bacilli sputum smear positivity in patients with multidrug-resistant pulmonary tuberculosis
}

\author{
Sidwell Mvo \\ Walter Sisulu University Faculty of Health Sciences \\ Benjamin Longo-Mbenza \\ Walter Sisulu University Faculty of Health Sciences \\ Sandeep D. Vasaikar \\ Walter Sisulu University Faculty of Health Sciences \\ Teke Apalata ( $\square$ ruffinapalata@gmail.com ) \\ Walter Sisulu University Faculty of Health Sciences
}

Research article

Keywords: MDR-TB; HIV status; time to sputum microscopy conversion; smear positivity

Posted Date: March 9th, 2020

DOI: https://doi.org/10.21203/rs.3.rs-16305/v1

License: (c) (i) This work is licensed under a Creative Commons Attribution 4.0 International License. Read Full License 


\section{Abstract}

Background The study sought to determine factors associated with prolonged smear positivity in multidrug-resistant tuberculosis (MDR-TB) patients following an appropriate management.

Methods Newly diagnosed patients [(100 MDR-TB and 100 drug-susceptible TB (DS-TB)] were enrolled between June 2017 and May 2018. Clinical and radiological findings were recorded. Sputum samples were collected for Xpert $\circledast$ MTB/RIF and line probe assays (LiPA). Microscopic tests, including smear grading, were performed at baseline, 4, 8 and 12 weeks post anti-TB therapy. Kaplan-Meier and Cox regression analyses were performed using SPSS v23 with $\rho$ set at $\leq 0.05$.

Results Of the 200 patients (median age of 34.8 years), 114 (57\%) were HIV positive. After 12 weeks of treatment, there was a significant microscopy conversion rate among DS-TB patients [43/45 (95.6\%)] as compared to MDR-TB patients [54/69 (78.3\%)] $(\rho=0.009)$, all coinfected with HIV. Similarly, among HIV negative patients, a significant microscopy conversion rate was noted among DS-TB patients [48/55(69.6\%)] as compared to MDR-TB patients [21/31(30.4\%)] $(\rho=0.03)$. Time to microscopy conversion was $4.58 \pm 2.97$ weeks and 5.69 \pm 3.25 weeks for HIV positive patients aged $\geq 35$ years and $<35$ years, respectively whilst among HIV negative patients, time to conversion was $5.00 \pm 2.83$ weeks and $6.86 \pm 3.59$ weeks for those aged $\geq 35$ years and $<35$ years, respectively $(\rho=0.003)$. There was a significant association between CD4+ T cell counts at initiation of TB treatment and smear microscopy conversion rates after 12 weeks $(\rho=0.010)$. At 8 weeks of anti-TB therapy, all MDR-TB patients whose baseline smear microscopy score ranged from scanty to $1+$ converted negative whilst $25 \%$ of patients with score $\geq 2+$ at baseline remained positive at the end of 12 weeks of treatment $(\rho=0.014)$. Multivariate Cox regression showed that only baseline smear microscopy grade was independently associated with prolonged smear positivity in MDR-TB patients at 12 weeks $(\rho=0.014)$.

Conclusion Baseline microscopy score $\geq 2+$ is key determinant for prolonged MDR-TB smear positivity beyond 12 weeks of anti-TB therapy. This indicator, though less sensitive than culture, can be used in poor resource settings.

\section{Background}

Ranged only behind India and Russia, South Africa occupies the third position because the country has the highest number of patients diagnosed with drug-resistant tuberculosis (DR-TB) in the world (1). The raise of DR-TB cases in South Africa and other parts of the world threatens the efforts to end TB (1). Globally, studies have shown that one of the major public health challenges today is the fact that numerous countries, particularly countries with limited resources, have the highest rates of multi-drug resistant tuberculosis (MDR-TB) and extensively-drug resistant tuberculosis (XDR-TB) $(2,3)$. It has been evident through various published reports that most of those MDR-TB and XDR-TB cases are driven by the HIV epidemic (2-3). In addition, the success response to anti-TB treatment has been also challenged. For example in 2014, reports underlined the fact that more than half of the total estimated cases of DR-TB were receiving anti-TB therapy, of which, only half achieved treatment success (2-3).

Among strategies able to reduce the transmission of tuberculosis (including MDR- and XDR-TB), early detection of cases and their effective management are proven to be the cornerstone approach for substantially preventing the occurrence of new TB cases (4-5). In patients diagnosed with TB, the conversion of microscopy smear is achieved when the initial positive result becomes negative following an appropriate anti-TB therapy (6). In order to achieve such conversion of smear microscopy during the first two months of the intensive care phase, patients' compliance to anti-TB drugs is mandatory, hence represents one of the most successful outcome of any TB control program (7-8). In settings with limited resources, smear conversion is therefore an important indicator for patient response to therapy since the use of culture techniques for monitoring patient response is costly (4). In addition to patient adherence to TB treatment, studies have shown that demographic factors (age, gender), HIV status, and initial level of infectiousness (measured by smear grade) are determinants for sputum conversion rate. HIV infected patients have $5-15 \%$ probability of developing active TB disease, making HIV co-infection one of the most significant risk factor for developing TB (2-3). It has been indicated that HIV prevalence in a setting is proportionally correlating with TB incidence. About 8\% of all new TB cases can be attributed to HIV (9). In 2018 in South Africa, HIV prevalence was estimated to 13\% at the population level whilst 6 out of 10 TB patients were found to be co-infected with HIV (10). Moreover, the probability of death was 2-times high likely to occur among TB and HIV co-infected patients as compared to HIV infected patients without TB, even after adjusting for the levels of their CD4 $+T$ cells and initiation of antiretroviral therapy (11).

In South Africa, the Xpert MTB/RIF (Cepheid, Sunnyvale, USA) has largely replaced direct smear microscopy for the routine detection of Mycobacterium tuberculosis even at primary care levels. However, the smear microscopy test remains useful in patients who are confirmed to have tuberculosis for the purpose of monitoring changes in the loads of M. tuberculosis observed during microscopy testing by means of smear grading, hence providing an indication to treatment response in patients whose initial smear-positivity results were determined (7-8).

Page 2/19 
Although finding acid-fast bacilli (AFB) is highly specific in confirming the diagnosis of smear positive tuberculosis, the viability of AFB seen can only be confirmed by cultures. Nevertheless, in many developing countries, microscopy conversion (from positive to negative results) is still considered as a predictor of survival and quality care because TB transmission is high likely to occur when a TB patient has a positive sputum microscopy. However, information from the literature pertaining to the time to sputum microscopy conversion among MDR-TB patients co-infected with HIV is scanty with enormous controversies. This study determined the impacts of HIV disease progression, baseline TB infectiousness rate, and demographic factors (age and gender) on rates and time to sputum microscopy conversion among MDR-TB patients following the initiation of an appropriate anti-TB therapy.

\section{Methods}

\section{Study setting, design and population.}

This was a retrospective cohort study. Patients attending health facilities in OR Tambo district whose sputum samples were received at National Health Laboratory services (NHLS) reference TB laboratory in Nelson Mandela Academic hospital were enrolled. Demographic (age, gender), clinical and radiological findings were recorded. A total of 200 newly diagnosed patients, of which 100 were MDR-TB and the other 100 DS-TB patients, were retained in the study. These patients were grouped according to their HIV status. For HIV positive patients, levels of immunosuppression were measured and classified as severe (CD4 <200 cells $\left./ \mathrm{mm}^{3}\right)$; advanced $\left(\mathrm{CD} 4=200-349 \mathrm{cells} / \mathrm{mm}^{3}\right)$; and mild (CD4 = 350-499 cells $\left./ \mathrm{mm}^{3}\right)(12)$.

\section{Microbiological testing}

Sputum samples (expectorated or induced) were collected from all new patients suspected of having TB. Specimens were transported into NHLS TB laboratory within 4 hours of collection, and were processed for GeneXpert MTB/RIF, Line Probe Assays (LiPA), and microscopy (Fluorescence microscopy and Ziehl Neelsen). Prior to process, macroscopic characteristics of sputum were determined as purulent, mucoid, saliva, or blood stained. Blood samples were collected for HIV testing and CD4+ T cell counts.

\section{Microscopic staining techniques}

Direct smears were prepared in duplicate, from sputum sediment after decontamination (by the sodium Hydroxide-N-Acetyl-L-Cysteine method), for staining by Ziehl Neelsen (Zn) carbol fuchsin and Fluorescent Auramine 0 staining techniques (13). Staining using ZN was carried out according to standard published procedures, and slides were examined with bright-field microscopy (Olympus CX21) using the $100 \mathrm{X}$ oil objective (10X eye piece for a total of $1000 \mathrm{X}$ magnification). For staining with Auramine $\mathrm{O}$, a fluorescent microscope was used and microscopists scanned the entire smear with the 20X objective (with 10X eyepiece for a total of 200X magnification). Using 20X magnification, one $2 \mathrm{~cm}$ length is equivalent to 30 fields, which is sufficient to report a negative result. The presence or absence of Acid fast bacilli (AFB) was reported using WHO/IUATLD guidelines (13). All smears were read by two microscopists involved in routine diagnostic services; in case of discrepant results, a third microscopist reviewed the slides. Positive (H37Rv strain) and negative (sterile distilled water) control slides were included with every batch of patient slides, and when new lots of stains are received.

Samples were initially examined using Fluorescent Auramine 0 staining technique. All positive results were thereafter confirmed using Ziehl Neelsen (Zn) carbol fuchsin technique. Smear microscopy results were used to estimate the levels of infectiousness of each patient at initiation of effective treatment (enrolment) and also during follow ups, at 4, 8 and 12 weeks.

\section{Molecular Methods}

The GeneXpert MTB/RIF assay (Cepheid, Sunnyvale, USA) was performed directly on TB samples using the version G4 of cartridges according to the manufacturer's recommendations. Two millilitres of the final samples were transferred into the Xpert MTB/RIF cartridge, and the latter was loaded into the GeneXpert instrument. Reported results were $M$. tuberculosis negative or positive and Rifampicin (RIF) resistant (presence of mutations in Rifampicin Resistance-Determining Region of M.tb) or susceptible (14).

Line probe assays (LiPA: Hain Lifescience, Nehren, Germany) was used to simultaneously diagnose TB and detect mutations conferring rifampicin and isoniazid resistance by detecting the presence of the DNA of Mycobacterium tuberculosis in the sputum and also identifying any mutations in the DNA that may cause rifampicin and/or isoniazid resistance. The test included the simultaneous detection of the most important rpoB mutations, which confer RIF resistance and katG and inhA mutations, which confer high-level and low level isoniazid (INH) resistance, respectively (14).

\section{HIV Testing and Definitions of HIV-Induced Immunosuppression}


Initial HIV test was performed on blood using the HIV rapid test Determine HIV-1/2/O (Abbott Laboratories, Abbott Park, IL). Patients with negative HIV results were re-tested 3 months later. All initial HIV positive samples were subsequently retested using a second HIV screening kit (ARCHITEC HIV Ag/Ab Combo Reagent Kits) and HIV confirmatory test kit using Eleyses HIV Combi kit (Abbot Architect Plus).

As part of the routine management of the patients, all HIV-infected patients benefited directly from CD4+ T cell count measurements and HIV viral loads. Absolute values of CD4+ T cell counts (cells $/ \mathrm{mm}^{3}$ ) were used to determine the degree or severity of immunocompromise following the World Health Organization (WHO) immunological staging criteria: CD4 levels $<200 / \mathrm{mm}^{3}$ (severe immunosuppression), CD4 levels 200-349/mm³ (advanced immunosuppression), and CD4 levels 350-499/mm³ (mild immunosuppression) (12, 15).

\section{Treatment regimens of DR-TB patients}

Patients diagnosed as MDR-TB or RMP-resistant TB, with or without additional resistance were initiated on standardised treatment given in two phases (intensive and the continuation phases) (14). The total duration of treatment for the MDR-TB regimen was function of either a short or long regimen was used. Each patient was treated with an individualized treatment regimen composed of second line injectable drugs (amikacin or capreomycin), fluoroquinolones (levofloxacin, ofloxacin or moxifloxacin), ethambutol, pyrazinamide, and high dose isoniazid. The short regimen included 4-6 months of Kanamycin (Km) -Moxifloxacin (Mfx) - Prothionamide (Pto) - Clofazimine (Cfz) Pyrazinamide (Z) -high-dose Isoniazid (H)-Ethambutol (E) followed by 5 months of Mfx-Cfz-Z-E; whilst the long regimen included 6 months of: Z-Km(Am)-Mfx-Eto-Terizidone (Trd) followed by 18 months of: Z-Mfx-Eto-Trd (14). Patients were reviewed at monthly intervals during the intensive phase, and at 3-monthly intervals during the continuation phase until the end of treatment.

\section{Data Variables and Statistical analysis}

Statistical Package for the Social Science (SPSS) version 23 was used for all statistical analyses. The level of significance was set at $\leq$ 0.05. Categorical variables were expressed as proportions (\%), and continuous (discrete ordinal) variables were presented as mean ( \pm standard deviation). For univariate analyses, the $X^{2}$ test was used to compare proportions, and analysis of variance (ANOVA) was used to compare groups, while the $\mathrm{R}$ coefficient was computed to analyse the correlations between quantitative variables. Kaplan-Meir analysis curves (survival curves) where constructed for microscopy conversion of HIV positive and HIV negative patients with MDR-TB receiving treatment. Smear microscopy results were used to estimate the proportion of smear negative patients at 4, 8 and 12 weeks. Finally, multivariate Cox regression analysis was used to identify independent determinants associated with sputum microscopy conversion.

\section{Results}

A total of 200 patients were enrolled in this study, of which 103 (51.5\%) were males and 97 (48.5\%) were females, with the sex ratio of 1 man: 1 woman. Out of these 200 patients, 55 (27.5\%) were aged $\geq 35$ years while $145(72.5 \%)$ were aged <35 years. The mean age of the study population was 34.8 ( \pm 11.6 ) years ranging from $18-67$ years. HIV test results were obtained from the 200 participants, of which 114 (57\%) tested HIV positive and 86(43\%) tested HIV negative. Of the 200 participants, 100 (50\%) were confirmed of having multidrug-resistant tuberculosis (MDR-TB) while the remaining 100 (50\%) patients were diagnosed with drug-susceptible tuberculosis (DS-TB).

\section{Sputum smear microscopy conversion rates and time-to-sputum conversion among HIV infected and uninfected patients:}

Table 1 below depicts the proportions of smear microscopy grades at baseline stratified by HIV sero-status of the participants. HIV infected and uninfected patients were matched by their smear microscopy grades at enrolment $(P=0.79)$.

Table 1 Proportions of smear microscopy grades at baseline by HIV status

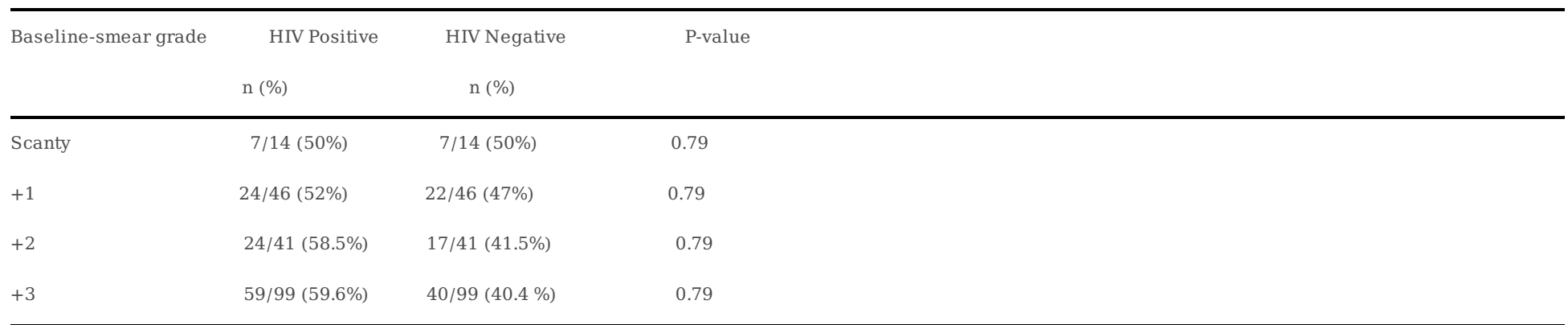


After 4 and 8 weeks of appropriate anti-TB treatment, there was no statistically significant difference in the smear microscopy conversion rates of HIV infected patients as compared to HIV uninfected patients. However, Table 2 below shows that after 12 weeks of appropriate anti-TB treatment, although there was no statistically significant difference $\left(X^{2}=3.227 ; P=0.358\right)$ in the sputum smear conversion rates of HIV infected patients versus HIV uninfected patients, the conversion rate was however higher (>90\%) among HIV infected patients whose baseline microscopy grade ranged from scanty to $2+$ as compared to patients who had a grade of $3+$ at baseline (conversion rate of $76 \%)(P$ = 0.049). In addition, after 12 weeks of treatment, there was also a significant microscopy conversion rate among DS-TB patients [43/45 (95.6\%)] as compared to MDR-TB patients [54/69 (78.3\%)] ( $P=0.009)$, all co-infected with HIV. Furthermore, among the HIV negative patients, data have also shown a significant microscopy conversion rate among DS-TB patients [48/55(69.6\%)] as compared to MDR-TB patients $[21 / 31(30.4 \%)](P=0.03)$.

Table 2. Proportions of negative cases (conversion rates) after 12 weeks of treatment according to HIV status

\begin{tabular}{|c|c|c|c|c|c|c|}
\hline \multirow[b]{2}{*}{ Variables of Interest } & \multicolumn{3}{|c|}{ HIV Positive $(n=114)$} & \multicolumn{3}{|c|}{ HIV Negative $(\mathrm{n}=86)$} \\
\hline & Smear Conv. & \multicolumn{2}{|c|}{ P-value } & \multicolumn{3}{|c|}{ Smear Conv. $\quad$ P-value } \\
\hline \multicolumn{7}{|l|}{ Gender } \\
\hline Male & $54 / 61(88.5 \%)$ & 0.20 & & $35 / 42(83.3 \%)$ & 0.33 & \\
\hline Female & $43 / 53$ (81.1\%) & 0.20 & & $34 / 44(77.3 \%)$ & 0.33 & \\
\hline \multicolumn{7}{|l|}{ Age } \\
\hline$\geq 35$ & $48 / 55(87.3 \%)$ & 0.36 & & $32 / 35$ (91.4 \%) & 0.27 & \\
\hline$<35$ & 49/59 (83.1\%) & 0.36 & & $37 / 51(72.5 \%)$ & 0.27 & \\
\hline \multicolumn{7}{|c|}{ Smear microscopy grade } \\
\hline Scanty & $7 / 7(100 \%)$ & 0.049 & & 7/7 (100 \%) & 0.28 & \\
\hline+1 & 22/24 (91.7 \%) & 0.049 & & $21 / 22(95.5 \%)$ & 0.28 & \\
\hline+2 & 23/24 (95.8 \%) & 0.049 & & $14 / 17$ (82.4 \%) & 0.28 & \\
\hline+3 & 45/59 (76.3 \%) & 0.049 & & $27 / 40(67.5 \%)$ & 0.28 & \\
\hline \multicolumn{7}{|c|}{ Baseline smear category } \\
\hline Scanty $\&+1$ & $7 / 7(100 \%)$ & 0.253 & & $7 / 7(100 \%)$ & 0.171 & \\
\hline$+2 \&+3$ & $90 / 107(84.1 \%)$ & 0.253 & & $62 / 79(78.5 \%)$ & 0.171 & \\
\hline \multicolumn{7}{|l|}{ TB status } \\
\hline MDR-TB & \multicolumn{2}{|c|}{$54 / 69(78.3 \%)$} & 0.009 & \multicolumn{2}{|c|}{$21 / 31(67.7 \%)$} & 0.030 \\
\hline DS-TB & \multicolumn{2}{|c|}{$43 / 45(95.6 \%)$} & 0.009 & \multicolumn{2}{|c|}{$48 / 55(87.3 \%)$} & 0.030 \\
\hline
\end{tabular}

Smear Conv $=$ Smear Conversion

Time to microscopy conversion was $4.58 \pm 2.97$ weeks and $5.69 \pm 3.25$ weeks for HIV positive patients aged $\geq 35$ years and below 35 years respectively while among HIV negative patients, time to conversion was $5.00 \pm 2.83$ weeks and $6.86 \pm 3.59$ weeks for those aged $\geq 35$ and below 35 years respectively $(P=0.003)$ as displayed in Figure 1 below.

\section{Correlations between levels of HIV-associated immune suppression and time to microscopy conversion:}

Of the 200 patients, 114 (57\%) were HIV infected of which we only obtained $\mathrm{CD}_{4}+\mathrm{T}$ cell count results from 51 patients. The mean $C D_{4}+\mathrm{T}$ cells for the 51 patients was 179.84 cells $/ \mathrm{mm}^{3}$, ranging from $3-487$ cells $/ \mathrm{mm}^{3}$, with a standard error of the mean (SEM) of 19.59 cells $/ \mathrm{mm}^{3}$ and standard deviation (SD) of 139.9 cells $/ \mathrm{mm}^{3}$. Of the $51 \mathrm{HIV}$ infected patients, $29(56.9 \%)$ had $\mathrm{CD}_{4}+\mathrm{T}$ cell count $\leq 200$ cells $/ \mathrm{mm}^{3}$ (severe immune suppression) while 17/51 (33.3\%) and 5/51(9.8\%) HIV infected patients had $\mathrm{CD}_{4}+\mathrm{T}_{\text {cell }}$ count of 200-349 cells $/ \mathrm{mm}^{3}$ (advanced immune suppression) and 350-499 cells $/ \mathrm{mm}^{3}$ (mild immune suppression), respectively.

All HIV infected MDR-TB patients who had a baseline $\mathrm{CD}_{4}+\mathrm{T}$ cell count $\geq 350$ cells $/ \mathrm{mm}^{3}$ at the beginning of anti-TB treatment had a sputum microscopy conversion from positive to negative after 12 weeks. There was a significant correlation $(P=0.010)$ between the levels of immune suppression (CD4 count at the beginning of anti-TB therapy) and smear microscopy conversion rates after 12 weeks of appropriate treatment as depicted in Table 3 and Figure 2. 
Table 3. Correlation between levels of immune-suppression by means of CD4 T cell count (cell/mm ${ }^{3}$ ) and sputum smears status among MDR-TB patients.

\begin{tabular}{|c|c|c|}
\hline \multicolumn{3}{|l|}{$\begin{array}{l}\text { CD4 Category } \\
\left(\text { Cells } / \mathrm{mm}^{3}\right)\end{array}$} \\
\hline$\leq 200$ & $26 / 28$ (92.9) & $2 / 28(7.1)$ \\
\hline $200-349$ & $10 / 17(58.8)$ & $7 / 17(41.2)$ \\
\hline $350-499$ & $5 / 5(100)$ & $0(0)$ \\
\hline
\end{tabular}

Time to conversion (in weeks) from smear microscopy positive to negative among the HIV+ co-infected with MDR TB is summarized in the Figure 3 below taking into account their levels of immune-suppression at the initiation of appropriate anti-TB therapy. All HIV patients who had the initial CD4 Count > 350 converted from sputum smear microscopy positive to negative. The patient whose CD4 Count was < 200 Cells $/ \mathrm{mm}^{3}$ had a conversion rate of $92.9 \%$ after 10 weeks of anti-TB treatment as compare to patient whose CD4 count was between 200 to 349 Cells $/ \mathrm{mm}^{3}$ who only achieved $60 \%$ conversion rate.

When the 51 HIV positive patients co-infected with MDR TB were categorized in two groups composed of Group 1: 28 (54.9\%) patients with CD4 $<200$ cells $/ \mathrm{mm}^{3}$ and Group 2: 23(45.1\%) patients with CD4 $\geq 200$ cells $/ \mathrm{mm}^{3}$; although patients with CD4<200 cells/mm ${ }^{3}$ converted faster than those with CD $4 \geq 200$ cells $/ \mathrm{mm}^{3}$ this difference did not reach statistical significance $(P=0.184)$ as depicted in the Figure 4 below.

Table 4 below depicts a significant correlation $(P=0.015)$ between the levels of immuno-suppression (CD4 count at the beginning of anti-TB therapy) and smear microscopy conversion rates after 12 weeks of appropriate treatment. In addition, time to microscopy conversion rate was shorter (4.25 \pm 2.43 ) among HIV positive patients whose CD4 counts $\leq 200$ as compared to those who had CD4 count between $200-$

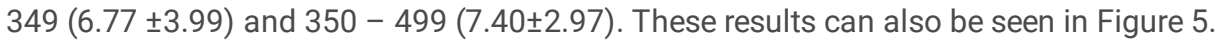

Table 4. Time to conversion between levels of immune-suppression by means of CD4 T-cell count $\left(\right.$ cells $\left./ \mathrm{mm}^{3}\right)$ and $\mathrm{HIV}$ status $(P=0.0015)$

\begin{tabular}{|c|c|c|c|c|}
\hline CD4 Count & $\mathrm{n}$ & Mean & SD & $(95 \% \mathrm{CI})$ \\
\hline$\leq 200$ & 28 & 4.25 & 2.43 & $(3.31-5.19)$ \\
\hline $200-349$ & 17 & 6.77 & 3.99 & $(4.71-8.82)$ \\
\hline $350-499$ & 5 & 7.40 & 2.97 & $(3.72-11.08)$ \\
\hline
\end{tabular}

\section{Prolongation of smear positivity in all TB patients at 12 weeks post-anti-TB initiation:}

Using bivariate analysis, Table 5 shows that at end of 12 weeks of appropriate anti-TB therapy, patients aged $<35$ years $(P=0.045)$, who had $2+$ to $3+$ baseline grade smear microscopy $(P<0.0001)$ and diagnosed with MDR-TB $(P=0.003)$, were significantly associated with a prolongation of smear positivity.

Figure 6 shows that at the end of 12 weeks of anti TB therapy, $9 \%$ of DS-TB patients remained positive versus $25 \%$ of MDR-TB counterparts $(P=0.003)$. However, Figure 7 shows that $87.9 \%$ of MDR TB patients who are aged $\geq 35$ years converted negative at the end of 12 weeks of anti TB therapy as compared to $78.2 \%$ of MDR Tb patient aged $<35$ years $(\mathrm{P}=0.045)$.

Table 5 Factors associated with prolongation of smear positivity in all TB patients at 12 weeks post-anti-TB initiation

\begin{tabular}{lcc}
\hline Variable of interest & Converted negative n (\%) & P-Value \\
\hline Gender & $89(86.4)$ & \\
Male & $77(79.4)$ & \\
Female & & 0.045 \\
Age & $80(87.9)$ & \\
$\geq 35$ & $86(78.2)$ & $<0.0001$ \\
$<35$ & & \\
Baseline smear microscopy & $14(100)$
\end{tabular}




\begin{tabular}{lll}
+1 & $43(93.5)$ & \\
+2 & $37(90.2)$ & \\
+3 & $77(72.7)$ & 0.003 \\
TB susceptibility & \\
MDR-TB & $75(75)$ & \\
DS-TB & $91(91)$ & \\
HIV status & & \\
Positive & $97(85.1)$ & \\
Negative & $69(80.2)$ & \\
\hline
\end{tabular}

As depicted in Table 6 and Figure 8, time to microscopy conversion from positive to negative was significantly influenced by the baseline smear grade result $(p<0.0001)$.

Table 6 Time to negative conversion in weeks by baseline smear microscopy for all patients diagnosed with TB $(P<0.0001)$

\begin{tabular}{|c|c|c|c|c|}
\hline Smear grade & $\mathrm{n}$ & mean & SD & $(95 \% \mathrm{CI})$ \\
\hline$\overline{\text { Scanty }}$ & 14 & 3.86 & 2.07 & $(2.66-5.05)$ \\
\hline+1 & 46 & 3.78 & 1.60 & $(3.41-4.26)$ \\
\hline+2 & 41 & 5.83 & 2.70 & $(4.98-6.68)$ \\
\hline+3 & 99 & 6.53 & 3.80 & $(5.77-7.28)$ \\
\hline
\end{tabular}

Table 7 below shows proportions of time to microscopy conversion rates over time among HIV infected and HIV uninfected TB patient receiving anti TB treatment. The proportions of TB patients who had negative microscopy results were not statistically significant after 4,8 and 12 weeks.

Table 7 Time to microscopy conversion rates in weeks by HIV status

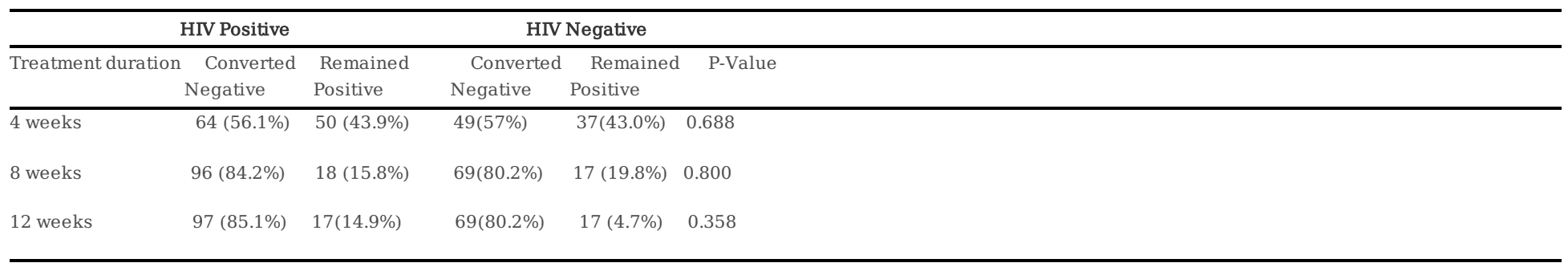

\section{Prolongation of smear positivity at 12 weeks post-anti-TB initiation in patients diagnosed with MDR-TB as compared to patients diagnosed} with drug susceptible TB:

In bivariate analysis, Table 8 below shows that baseline smear microscopy grade $(P=0.014)$ and initial CD4 T cells category $(P=0.010)$ were significantly associated with the prolongation of smear positivity in MDR-TB patients (versus DS-TB patients) at the end of 12 weeks' posttherapy.

In addition, time to microscopy conversion in patients diagnosed with MDR-TB was significantly prolonged as compared to patients diagnosed with DS-TB irrespective of their HIV status $(P=0.001)$ as shown in Table 9 and Figure 9 below.

Table 8 Factors associated with prolongation of smear positivity at 12 weeks post-anti-TB initiation in patients diagnosed with MDR-TB as compared to patients 


\begin{tabular}{|c|c|c|c|c|c|c|}
\hline \multirow[b]{2}{*}{ Lbles of interest } & \multicolumn{3}{|c|}{ MDR-TB patients } & \multicolumn{3}{|c|}{ DS-TB patients } \\
\hline & \begin{tabular}{|l|} 
Converted negative (\%) \\
\end{tabular} & Remained positive (\%) & $p$-value & Converted negative (\%) & Remained positive (\%) & $p$-value \\
\hline $\begin{array}{l}\text { Male } \\
\text { Female }\end{array}$ & $\begin{array}{l}41 / 52(78.8) \\
34 / 48(70.8)\end{array}$ & $\begin{array}{c}11(21.2) \\
14(29.2)\end{array}$ & 0.355 & $\begin{array}{c}48 / 51(94.1) \\
43 / 49(87.8)\end{array}$ & $\begin{array}{l}3(5.9) \\
6(12.2)\end{array}$ & 0.266 \\
\hline $\begin{array}{l}\text { ears } \\
\quad \geq 35 \\
<35 \\
\end{array}$ & $\begin{array}{l}35 / 42(83.3) \\
40 / 58(69.0)\end{array}$ & $\begin{array}{c}7(16.7) \\
18(31.0)\end{array}$ & 0.101 & $\begin{array}{l}45 / 48 \text { (93.8) } \\
46 / 52 \text { (88.5) }\end{array}$ & $\begin{array}{l}3(6.3) \\
6(11.5)\end{array}$ & 0.356 \\
\hline $\begin{array}{l}\text { ine smear } \\
\text { Scanty } \\
+1 \\
+2 \\
+3\end{array}$ & $\begin{array}{c}8 / 8(100) \\
15 / 17(88.2) \\
13 / 14(92.9) \\
39 / 61(63.9)\end{array}$ & $\begin{array}{c}0(0) \\
2 / 17(11.8) \\
1 / 14(7.1) \\
22 / 61(36.1)\end{array}$ & 0.014 & $\begin{array}{c}6 / 6(100) \\
28 / 29(96.6) \\
24 / 17(88.9) \\
33 / 38(86.8)\end{array}$ & $\begin{array}{c}0(0) \\
1 / 29(3.4) \\
3 / 27(11.1) \\
5 / 38(13.2)\end{array}$ & 0.452 \\
\hline $\begin{array}{l}\text { ine smear } \\
\text { Scanty and }+1 \\
+2 \text { and }+3\end{array}$ & $\begin{array}{r}8 / 8(100) \\
67 / 92(72.8)\end{array}$ & $\begin{array}{c}0(0) \\
25 / 92(27.2)\end{array}$ & 0.089 & $\begin{array}{r}6 / 6(100) \\
85 / 94(90.4)\end{array}$ & $\begin{array}{c}0(0) \\
9 / 94(9.6)\end{array}$ & 0.427 \\
\hline $\begin{array}{l}\text { T cell groups } \\
\quad<200 \text { cells } / \mu l \\
\geq 200 \text { cells } / \mu l\end{array}$ & $\begin{aligned} & 26(92.9) \\
49 & (68.1)\end{aligned}$ & $\begin{array}{r}2(7.1) \\
23(31.9)\end{array}$ & 0.010 & - & - & - \\
\hline $\begin{array}{l}\text { atus } \\
\text { Positive } \\
\text { Negative }\end{array}$ & $\begin{array}{r}54 / 69(78.3) \\
21 / 31(67.7)\end{array}$ & $\begin{array}{c}15(21.7) \\
10(32.3)\end{array}$ & 0.261 & $\begin{array}{c}43 / 45(95.6) \\
48 / 55(87.3)\end{array}$ & $\begin{array}{l}2 / 45(4.4) \\
7 / 55(12.7)\end{array}$ & 0.150 \\
\hline
\end{tabular}

Table 9 Time to microscopy conversion (weeks) by HIV status in MDR-TB patients versus DS-TB patients $(P=0.001)$

\begin{tabular}{lccc}
\hline HIV \& MDR status & n & Mean & SD $(95 \%$ CI $)$ \\
\hline HIV (-) \& MDR (-) & 55 & 5.49 & $2.99(4.68-6.30)$ \\
HIV (-) \& MDR (+) & 31 & 7.19 & $3.87(5.78-8.61)$ \\
HIV (+) \& MDR (-) & 45 & 4.13 & $1.99(3.53-4.73)$ \\
HIV (+) \& MDR (+) & 69 & 5.83 & $3.59(4.97-6.69)$ \\
\hline
\end{tabular}

Furthermore, among MDR-TB patients, time to microscopy conversion in patients aged <35 years was significantly prolonged as compared to patients aged $>35$ years $(P=0.004)$ as shown in Table 10 and Figure 10 below.

Table 10 Time to conversion in week by age category $(\mathrm{P}=0.004)$

\begin{tabular}{|c|c|c|c|}
\hline Ages (years) & $\mathrm{n}$ & Mean & $\mathrm{SD} \quad(95 \% \mathrm{CI})$ \\
\hline $18-24$ & 41 & 6.88 & $3.50(5.78-7.98)$ \\
\hline $25-34$ & 69 & 5.86 & $3.39(5.04-6.67)$ \\
\hline $35-44$ & 52 & 4.94 & $2.97(4.12-5.77)$ \\
\hline
\end{tabular}

In multivariate analysis, Cox regression showed that only the baseline smear microscopy grade was independently associated with prolonged smear positivity in MDR-TB patients at 12 weeks $(\rho=0.014)$, after adjusting for HIV status, CD4 count and age. As depicted in Figure 11, Cox regression analysis has shown that at the end of 8 weeks on anti TB therapy, all MDR TB patients who had a baseline smear microscopy form scanty to +1 converted negative whilst $25 \%$ of patients with +2 and +3 remained positive until the end 12 weeks of treatment $(P=0.014)$.

\section{Discussion}

In South Africa and other countries with limited resources, despite numerous efforts and progress made, DR-TB remains not only a public health challenge but also an economic challenge since the management of DR-TB cases is extremely costly as compared to drug sensitive TB $(5,16)$. This situation is worsening by the presence of a large HIV epidemic in these settings but also the astronomic rise of cases of 
MDR-TB and XDR-TB $(5,16)$. Since regular cultures of patients' specimens are not cost effective in order to monitor patients' response to therapy, smear conversion is still effectively used as an indicator in many countries with limited resources (17). Healthcare workers in settings with limited resources rely on findings from smear microscopy grading to make clinical decisions. The present study was conducted in order to gain insight into delayed time and rate to sputum smear conversion, particularly in the face of dual MDR/XDR-TB and HIV epidemics, as proxy indicator of persistence level of TB infectiousness. Factors associated with delays in smear conversion from positive to negative were also explored.

Anecdotal evidence has been suggesting that DR-TB patients, when co-infected with HIV become more infectious with less response to treatment as compared to DR-TB patients who are HIV negative. Although previous studies conducted elsewhere have refuted this assumption, it was necessary to test the hypothesis in settings where dual DR-TB and HIV epidemics are prevalent and resources are limited.

Our results have shown that after 8 weeks of appropriate anti-TB treatment, there was no significant difference in the smear microscopy conversion rates of HIV infected patients as compared to HIV uninfected patients. Furthermore, it is shown that after 8 weeks of treatment, one patient out of every six treated remained potentially infectious, irrespective of the HIV status. This is in contrary to the general belief that patients become non-infectious after two weeks of standard treatment regimen. Our findings are in line with other results, which have also shown that the smear conversion from positive to a negative does not always occur sooner post-therapy in all patients (18, 19). In Tanzania for example, after two weeks on anti-TB treatment, investigators reported a significant microscopy conversion in HIV positive patients as compared to HIV negative patients (19). From our results it is also shown that after 2 weeks of treatment, conversion rate was significantly higher in HIV-positive than HIV-negative patients. Lack of delays in sputum smear conversion of TB patients co-infected with HIV has been previously reported $(20,21)$. However, HIV co-infected TB patients might even have an early sputum smear conversion (21). For example, a Malawian study has indicated that a shorter smear conversion time was significantly found among HIV infected study participants (22). In this study, HIV-negative TB patients were at higher risk for 8 weeks sputum smear non-conversion than their HIV positive counterparts. It could be due to the fact that since medical specialist manages DR-TB, patients strongly benefit from extensive adherence training because these DR-TB patients who are also HIV co-infected benefit from numerous support obtained from various stakeholders which are influencing their adherence to treatment, hence shorten the time to sputum conversion. Similar findings were supported by studies in Tanzania (19), and Uganda (20) where the authors reported that the co-infection with HIV has not been found to be significantly associated with delays in smear conversion rate or time to conversion $(18,19)$.

In this present study, although there was no significant difference in the sputum smear conversion rates of HIV infected patients versus HIV uninfected patients, the conversion rate was however higher (>90\%) among HIV infected patients whose baseline microscopy grade ranged from scanty to $2+$ as compared to patients who had a grade of $3+$ at baseline (conversion rate of $76 \%$ ).

At 8 weeks, $82.5 \%$ of all our study participants converted negative. Two distinct Indian studies reported two completely different conversion rates at the end of 8 weeks: whilst the conversion rate for the first study was very low (58\%) (23), the second study showed higher conversion rate (84\%), similar to the conversion rate found in this present study (24). It is estimated that more than $20 \%$ of smear-positive patients remain infectious after 2 months of treatment $(25,26)$. Studies done in many settings have shown that proportions of sputum smear non-conversion at the end of the intensive phase of TB treatment range from $5-32 \%(27,28)$.

In this study, acid fast smear positivity status was also assessed in correlation with CD4 count. Paradoxically, HIV positive patients with CD4 $<200$ cell $/ \mathrm{mm}^{3}$ converted faster than those with CD4 $\geq 200$ cells $/ \mathrm{mm}^{3}$. All HIV infected MDR-TB patients who had a baseline CD $4+T$ cell count $\geq 350$ cells $/ \mathrm{mm}^{3}$ at the beginning of anti-TB treatment had a sputum microscopy conversion from positive to negative after 12 weeks. The benefits of starting ART early irrespective of the CD4 + T cells cannot over emphasized. In South Africa, HIV infected women who are pregnant as well as TB patients who are HIV co-infected are started on ART on diagnosis irrespective of CD4 count (29).

Currently, the duration of MDR-TB infectiousness after the initiation of effective treatment is still a subject of discussion. Measures are to be maintained until non-infectiousness has been demonstrated. Guidelines from the Centers for Disease Control and Prevention highlighted that patients diagnosed with drug-susceptible tuberculosis can be considered non-infectious after at least two weeks of appropriate anti-Tb therapy in the presence of clinical improvement, and in a setting where the prevalence of DR-TB is very low (30). However, TB indicators by the World Health Organization suggest that patients diagnosed with new smear positive pulmonary tuberculosis should be estimated to convert to smear negative only after 2 to 3 months following the initiation of anti-TB treatment $(2,3,6)$. In addition, demonstration of noninfectiousness is best achieved by obtaining negative culture conversion results $(2,3,6)$. Unfortunately, particularly in resource limited settings, the time required to report culture results and the unavailability or scarcity of resources are major limitations to the use of culture for the purpose of infection prevention and control. On the other hand, sputum smear microscopy, though less sensitive than culture, can be reported much earlier but the presence of positive microscopy does not necessary indicate the presence of living mycobacteria, hence risk of infectiousness. 
For most of our patients who were diagnosed with drug susceptible tuberculsosi (DS-TB) versus MDR-TB, the conversion rate was $91 \%$ and $75 \%$ respectively. A study by DeRiemer et al. reported a cure rate of $73 \%$ when managing MDR-TB patients (31). The present study shows that potential TB infectiousness decreases from the baseline to $56.5 \% ; 82.5 \%$ and $83.0 \%$ at the end of 4 weeks, 8 weeks and 12 weeks, respectively. Our smear conversion rate at the end of 12 weeks (83\%) was shown to be higher than the reported $80.0 \%$ in Taiwan (32) but lower than the $98.6 \%$ found during a study in Tanzania (19); and also lower than the $92 \%$ rate reported by Bawri et al. (20).

The present study shows that the age group $<35$ years was an independent predictor of non-conversion of sputum smears among our smear positive TB patients after the initial anti-TB treatment. This is in contrary to numerous other studies which reported that the elderly was the least likely to have documented sputum conversion $(25,33-35)$. These authors have identified the age $\geq 40$ years as significant risk factor for the lack of smear conversion from positive to negative, particularly during the intensive treatment phase (25, 33-35). Furthermore, Singla et al pointed out that patients aged above 60 years and between 40-60 years had six-times and two-times, respectively, higher risk of not achieving smear conversion negative as compared to patients aged less than 40 years (25). The reasons for these differences is not clear.

Another independent risk factor for non-conversion identified in this present study was a higher smear grade (3+) at baseline; and this was irrespective of HIV status. A higher smear grade at baseline has also been identified in other studies as a predictor for non-conversion after 2 months of treatment $(4,17,25,26,36)$. According to the authors, heavy initial bacillary load has been documented as an important risk factor of delay in sputum smear conversion at the end of intensive phase of TB treatment. They argued that delayed treatment onset is associated with higher bacillary load at diagnosis, which in turn is related to higher sputum smear non-conversion $(4,17,25,26,36)$.

Many other reasons can also explain the non-conversion of sputum smear at the end of 12 weeks of treatment. First of all, "non-viable bacteria can remain visible under the microscope. Ideally, culture is the best method to evaluate the viability of M. tuberculosis" (37). "Unfortunately, this method is not practical in resource-limited settings such as in developing countries where TB is prevalent. Moreover, a study has shown a good correlation between culture and sputum acid-fast bacilli smear" (22).

Other potential explanations of non-conversion of sputum smear at end of 12 weeks' treatment are poor supervision of the initial phase therapy, poor treatment adherence by patients, doses of anti-TB drugs below recommended range, co-morbid conditions, drug resistant M. tuberculosis that is not responding to first-line treatment and heavy initial bacillary load $(4,17,25,26,36)$. The presence of lung cavitation in a TB patient is a well-recognized risk factor of delayed conversion and treatment failure in TB due to decrease penetration and antibacterial activity of drugs $(21,38,39)$.

The intensive phase completion conversion rate of $83 \%$ demonstrated in this study compares well with the expected rate, ranging between $80 \%$ and $90 \%$, among MDR-TB patients who are put on appropriate therapy and comply fully with treatment instructions. "With full patient compliance and strict adherence to therapeutic instructions, it is anticipated that 80 to $90 \%$ of infected patients will respond to therapy and become smear negative within 2-3 months of treatment" (40).

\section{Conclusions}

The present study has showed that a sizable proposition of MDR-TB patients did not convert to a negative smear result at the end of 8 weeks, and that HIV-seropositive status is not a principal factor in delaying sputum conversion among patients receiving intensive phase tuberculosis treatment. The key reason found for non-conversion remains the heavy initial bacillary load. As a result, MDR-TB patients with heavy initial bacillary load should thus be closely monitored and healthcare professionals should maintain infection prevention measures until conversion occurs.

The WHO encourages the use of rapid molecular techniques for providing the molecular characteristics of certain critical pathogens. Not only that the clinical decision making process for each TB case will be improved, but facilities will achieve higher success in terms of MDRTB monitoring and evaluation of adherence to anti-TB therapy, periodic surveillance of regional drug resistance status among TB patients.

Infection prevention and control measures are recommended for all sputum smear-positive patients to minimize the spread of infection. Measures are to be maintained until non-infectiousness has been demonstrated. Patients with heavy initial bacillary load should thus be closely monitored.

Limitations the study included the presence of missing data, mainly data on CD4 count and HIV plasma viral load results. Further, culture is the best method to evaluate the viability of $M$. tuberculosis and if performed, could have helped in drawing more accurate conclusions. However, we compared patients with DS-TB versus MDR-TB smear conversion rates and time to conversion and used multivariate Cox regression models to rule out confounders. 


\begin{tabular}{|c|c|}
\hline AFB & Acid-fast bacilli \\
\hline MDR-TB & Multidrug-resistant tuberculosis \\
\hline DS-TB & Drug-susceptible tuberculosis \\
\hline XDR-TB & extensively-drug resistant tuberculosis \\
\hline HIV & Human immunodeficiency virus \\
\hline PTB & Pulmonary tuberculosis \\
\hline NHLS & National Health Laboratory Services \\
\hline CD4 & Cluster of differentiation 4 \\
\hline LiPA & Line probe assay \\
\hline ZN & Ziehl Neelsen \\
\hline WHO & World Health Organization \\
\hline IUATLD & International union against tuberculosis and lung diseases \\
\hline Mtb & Mycobacterium tuberculosis \\
\hline ANOVA & Analysis of variance \\
\hline SD & Standard deviation \\
\hline $\mathrm{Cl}$ & Confidence interval \\
\hline
\end{tabular}

\section{Declarations}

\section{- Ethics approval and consent to participate}

Ethical clearance was obtained from the Research Ethics and Biosafety Committee of the Faculty of Medicine at Walter Sisulu University (Ethics Ref.No.107/2014) and permissions to conduct the study were obtained from the hospital management at Nelson Mandela Academic hospital in Mthatha complex and from the National Health Laboratory Services (NHLS). Patients were enrolled following an informed consent, and in order to protect privacy and confidentiality of patients, no names were recorded and instead, a personalized research number was used for each patient and only investigators had access to the collected data.

\section{- Consent for publication}

Not applicable.

\section{- Availability of data and materials}

The datasets used and/or analyzed during the current study are available from the corresponding author on reasonable request.

\section{- Competing interests}

The authors declare that they have no competing interests.

\section{- Funding}

Not applicable.

\section{- Authors' contributions}


SM wrote the study proposal, collected data, participated in data analysis and wrote the initial draft of this manuscript. BL performed data analysis and interpretation. SDV contributed in the design of the study and data collection. TA conceived the study and its design, participated in data analysis and interpretation and edited the final draft of the manuscript.

\section{- Acknowledgements}

We thank the staff at MDR-TB clinic, NHLS TB laboratory and WSU microbiology laboratory for supporting this project.

\section{References}

1. Maharaj, J, Ross A, Maharaj NR, Campbell L. Multidrug-resistant tuberculosis in KwaZulu-Natal, South Africa: An overview of patients' reported knowledge and attitudes. Afr J Prm Health Care Fam Med. 2016;8(1), a1089.

2. World Health Organization. Multidrug and extensively drug-resistant TB (M/XDR-TB): 2016 global report on surveillance and response. WHO/HTM/TB/2016.13. Geneva, Switzerland: WHO; 2016.

3. World Health Organization. The impact of the roll-out of rapid molecular diagnostic testing for tuberculosis on empirical treatment in Cape Town, South Africa. Bulletin WHO, 2017 (95): 545-608.

4. Caetano, MP, Carvalho, A, Valente. I, Braga, R, \& Duarte, R 2012, 'Predictors of delayed sputum smear and culture conversion among a Portuguese population with pulmonary tuberculosis', Revised Port Pneumol vol.18, pp. 72-79.

5. Harries, AD, Lawn, SD, Getahun, H, Zachariah. R, \& Havlir, DV 2012, 'HIV and tuberculosis-sis-science and implementation to turn the tide and reduce deaths', Journal International AIDS Soc 15, 17396.

6. World Health Organisation (WHO). Treatment of tuberculosis: guidelines. 4th ed. Geneva: WHO; 2010. WHO/HTM/TB/2009.420 http://whqlibdoc.who.int /publications/2010/9789241547833_eng.pdf. Accessed 02 January 2020.

7. National Department of Health. The South African National Tuberculosis Control Programme: Practical Guidelines. 2008. http://www.kznhealth.gov.za/chrp/documents/Guidelines/Guidelines\%20National/Tuberculosis/SA\%20TB\%20Guidelines\%202008.pdf.

8. National TB Management Guidelines. National Department of Health, 2014. (Accessed 15 April 2016, at http://www.health-e.org.za/wpcontent/uploads/2014/06/NTCP_Adult_TB-Guidelines-27.5.2014.pdf.)

9. Corbett, EL, Watt, CJ, Walker, N, Maher, D, Williams, BG, Raviglione, MC, \& Dye, C 2003,'The growing burden of tuberculosis: global trends and interactions with the HIV epidemic', Arch Intern Med, vol.163, pp.1009-1021.

10. Centers for Disease Control and Prevention. CDC's HIV/AIDS Care and Treatment Programs in South Africa. 2018 CDC Weekly newsletter. Accessed at: https://www.cdc.gov/globalhealth/countries/southafrica/what/tb_hiv.htm (20 January 2020).

11. Gaur, SN, Dhingra, VK, Rajpal, S 2004, 'Tuberculosis in the elderly and their treatment outcome under DOTS', Indian Journal Tuberculosis, vol.51, pp.83-87.

12. World Health Organization, Interim WHO Clinical Staging of HIV/AIDS and HIV/AIDS Case Definitions for Surveillance, WHO, 2005.

13. Rieder HL, Deun Av, Kam KM, Kim SJ, Chonde TM, et al. (2007) Priorities for tuberculosis bacteriology services in low-income countries: International Union Against Tuberculosis and Lung Disease.

14. Fotso, CB., Vasaikar, SD., and Apalata, T. (2018) Outcomes and Risk Factors Associated with Drug Resistant Tuberculosis in Rural Eastern Cape, South Africa. American Journal of Infectious Diseases, Volume 14(2); Pp: 69-76.

15. , T., Carr, WH., Sturm, AW., Longo-Mbenza,B., and Moodley, P. Determinants of Symptomatic Vulvovaginal Candidiasis among Human Immunodeficiency Virus Type 1 Infected Women in Rural KwaZulu-Natal, South Africa. Infectious Diseases in Obstetrics and Gynecology Volume 2014, Article ID 387070, 10 pages.

16. Norbis, L, Miotto, P, Alagna, R, \& Cirillo, DM 2013, 'Tuberculosis: lights and shadows in the current diagnostic landscape', New Micro-biol, vol.36, pp. 111-120.

17. Horne, DJ, Johnson, CO, Oren, E, Spitters, C \& Narita, M 2010, 'How soon should patients with smear-positive tuberculosis be released from inpatient isolation'? Infect Control Hosp Epidemiol. vol.31, pp. 78-84.

18. Fortun, J, Martin, DV, Molina, A, \& Navas, E 2007, 'Sputum conversion among patients with pulmonary tuberculosis: are the implications for removal of respiratory isolation'? Journal of Antimicrobial Chemotherapy, vol .59, pp.794-798.

19. Senkoro, M, Mfinanga, SG, \& Mørkve, 0 2010, 'Smear microscopy and culture conversion rates among smear positive pulmonary tuberculosis patients by HIV status in Dar es Salaam, Tanzania', BMC Infectious Disease, vol. 10, pp.10.

20. Bwire, R, Borgdorff, MW, \& Sticht-Groh, V 1999, 'Tuberculosis chemotherapy and sputum conversion among HIV seropositive and HIV seronegative patients in south-eastern Uganda,' East Africa Medical Journal, vol. 76, pp. 307-313.

Page $12 / 19$ 
21. Telzac, EE, Fazal, BA, Pollard, CL, Turett, GS, \& Justman, JE, Blum, S 1997, 'Factors influencing time to sputum conversion among patients with smear-positive pulmonary tuberculosis', Clinical Infectious Disease, vol. 25, pp. 666-670.

22. Domínguez-Castellano, A, Muniain, MA, Rodriguez-Baño, J, Garcia, M, Rios, MJ, \& Galvez, J 2003, 'Factors associated with time to sputum smear conversion in active pulmonary tuberculosis', International Journal Tuberculosis Lung Disease, vol. 7, pp. 432-438.

23. Rekha, BVV, Balasubramanian, R, Swaminathan, S, \& Rahman, RRF 2007, 'Sputum conversion at the end of intensive phase of Category1 regimen in the treatment of pulmonary tuberculosis patients with diabetes mellitus or HIV infection: An analysis of risk factors,' Indian Journal Med Res, vol. 126, pp. 452-458.

24. Bawn, S, Ali, S, Tayal, B, \&P. Baruwa 2008,'A study of sputum conversion in new smear positive pulmonary tuberculosis cases at the monthly intervals of 1 st, 2nd \& 3rd month under directly observed treatment, short course (dots) regimen Lung India', vol.25, no. 3, pp. 118-123.

25. Singla, R, Osman, MM, Khan, N, Al-Sharif, N, Al-Sayegh, MO, \& Shaikh, MA 2003, 'Factors predicting persistent sputum smear positivity among pulmonary tuberculosis patients 2 months after treatment', International Journal Tuberculosis Lung Disease, vol. 7, pp. 58-64.

26. Wang, JY, Lee, LN, Yu, CJ, Chien, YJ, Yang, PC \& Group, T 2009, 'Factors influencing time to smear conversion in patients with smear positive pulmonary tuberculosis', Respirology, vol.14, pp.1012-1019.

27. Jayakody, W, Harries, AD, \& Malhotra, S 2013, 'Characteristics and outcomes of tuberculosis patients who fail to smear convert at two months in Sri Lanka', Public Health Action, vol. 3, pp.26-30. doi:10.5588/pha.12.0090.

28. Kuyp, VF, \& Mahan, CS 2012, 'Prolonged positivity of sputum smears with negative cultures during treatment for pulmonary tuberculosis', International Journal Tuberculosis Lung Disease, vol.16, pp.1663-1667.

29. Grabar, S, Selinger-Leneman, H, Abgrall, S, Pialoux, G, Weiss, L, Costagliola, D 2009, ‘Prevalence and comparative characteristics of longterm nonprogressors and HIV controller patients in the French Hospital Database on HIV', AIDS, vol.23, no .9, pp.1163-1169. Available at http://www.ncbi.nlm.nih.gov/pubmed/19444075.

30. Centers for Disease Control and Prevention 2005, 'Guidelines for preventing the transmission of Mycobacterium tuberculosis in healthcare settings', Morbidity and Mortality Weekly Report, vol. 54, no. 17, pp. 1-141.

31. DeReimer, K, Garcia-Garcia, L, Bobadilla-de-Valle, Martinez, M 2005,'Does DOTS work in population with drug-resistant tuberculosis,'vol.365 no.9466. pp.1239-1245.

32. Su, WJ, Feng, JY, Chiu, YC, Huang, SF, \& Lee, YCI 2011, 'Role of 2-month sputum smears in predicting culture conversion in pulmonary tuberculosis', Eur Respir J, vol. 37, pp.376-383.

33. Lee J, Lee BJ, Yoon HI, Lee C-T, Lee JH 2012. Influence of previous tuberculosis treatment history on acid-fast bacilli smear and culture conversion. Int JTuberc Lung Dis, vol.16, no. 10: pp.1344-1338.

34. Liu, Z, Shilkret, KL, Ellis, HM 1999, 'Predictors of sputum culture conversion among patients with tuberculosis in the era of tuberculosis resurgence', Arch Intern Med, vol. 159, pp. 1110-1116.

35. Kuaban, C, Bame, R, Mouangue, L, Djella, S, \& Yomgni, C 2009, 'Non-conversion of sputum smears in new smear positive pulmonary tuberculosis patients in Yaoundé, Cameroon,' East African Medical Journal, vol.86, no.5, pp.219-225. 220300509b6ef.

36. Gopi, PG, Chandrasekaran, V \& Subramani, R 2006, 'Association of conversion \& cure with initial smear grading among new smear positive pulmonary tuberculosis patients treated with Category I regimen', Indian Journal Med Res, vol. 123, pp. 807-808.

37. Bouti, K, Aharmim, M, Marc, K, \& Saoualhi, M 2013, 'Factors influencing sputum conversion among smear positive pulmonary tuberculosis patients in Morocco,' ISRN Pulmonology, 2013: 5.doi:10.1155/2013/486507.

38. Dorman, SE, Johnson, JL, Goldberg, S, Muzanye, G, Padayachi, N 2009,'Substitution of moxifloxacin for isoniazid during intensive phase treatment of pulmonary tuberculosis.' Am J Respir Crit Care Med, vol.133, no.5, pp.273-280.

39. Yew, WW, Chan, CK, Chau, CH, Tam, CM, Leung, CC 2000, 'Outcomes of patients with multidrug resistant tuberculosis treated with ofloxacin/levofloxaxin- containing regimens. 'Chest, vol.117, pp.744-751.

40. Friedland, G, Churchyard, GJ, Nardell, E 2007,'Tuberculosis and HIV Coinfection: Current State of Knowledge and Research Priorities.' Journal of Infectious Diseases vol. 196, no.1; pp. S1-S3.

\section{Figures}




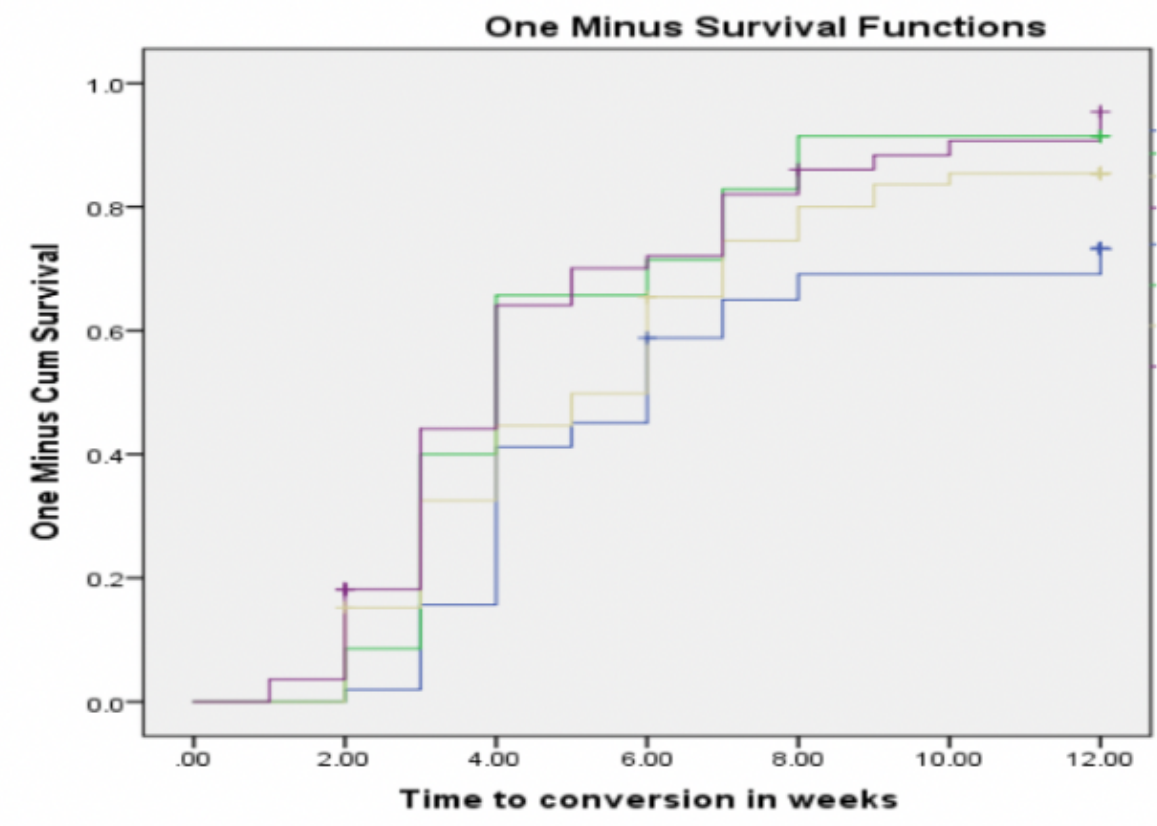

HIV status and Age groups

$\neg$ HIV(-) and Age $<35$ years

$-\mathrm{HIV}(-)$ and $\mathrm{Age}>=35$ years

HIV ( + ) and $A g e<35$ years

$\mathrm{HIV}(+)$ and Age $>=35$

years

HIV $(-)$ and Age $<35$ years-

censored

HIV $(-)$ and Age $>=35$

years-censored

$\mathrm{HIV}(+)$ and Age $<35$ yearscensored

HIV $(+)$ and Age $>=35$

years-censored

Figure 1

Sputum smear conversion rates and time-to-conversion (in weeks) by HIV status and age groups

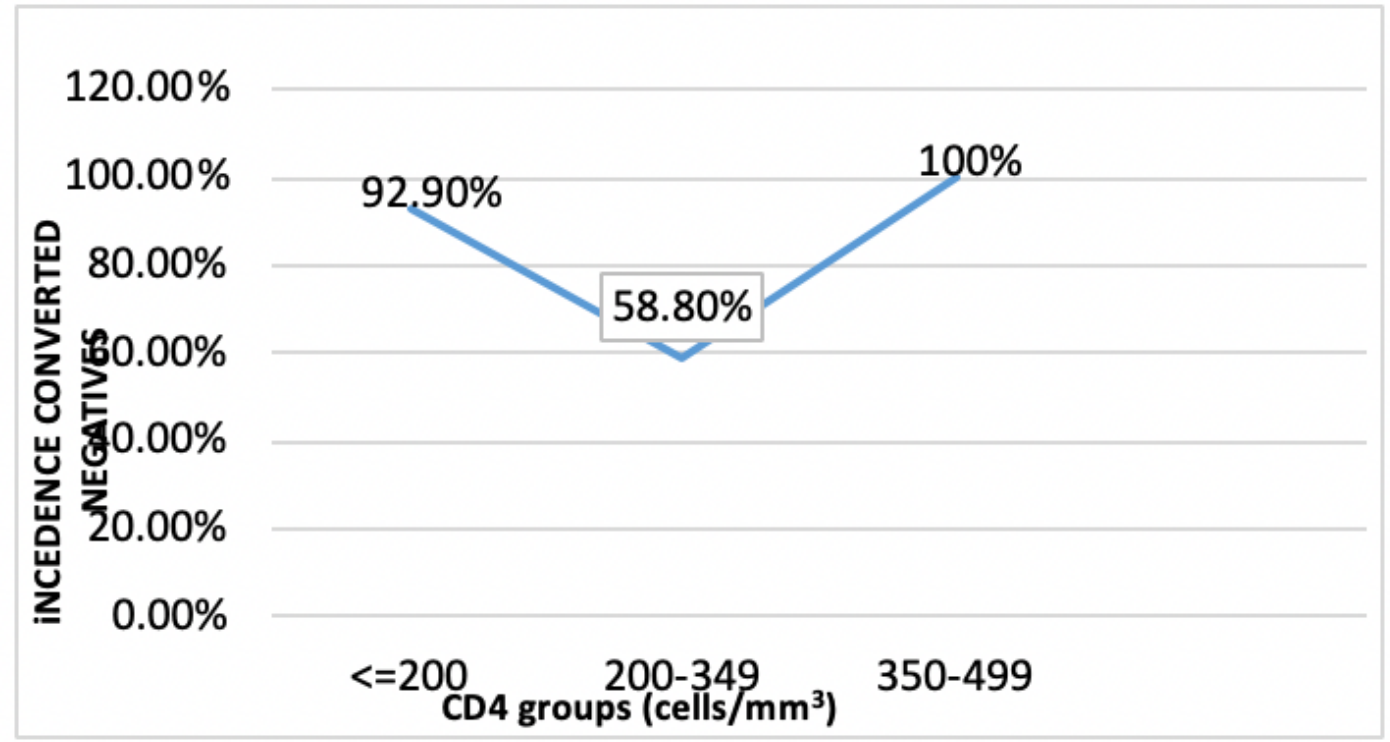

Figure 2

Distribution of proportions of TB patients converted negatives by CD4+ T cell count categories 


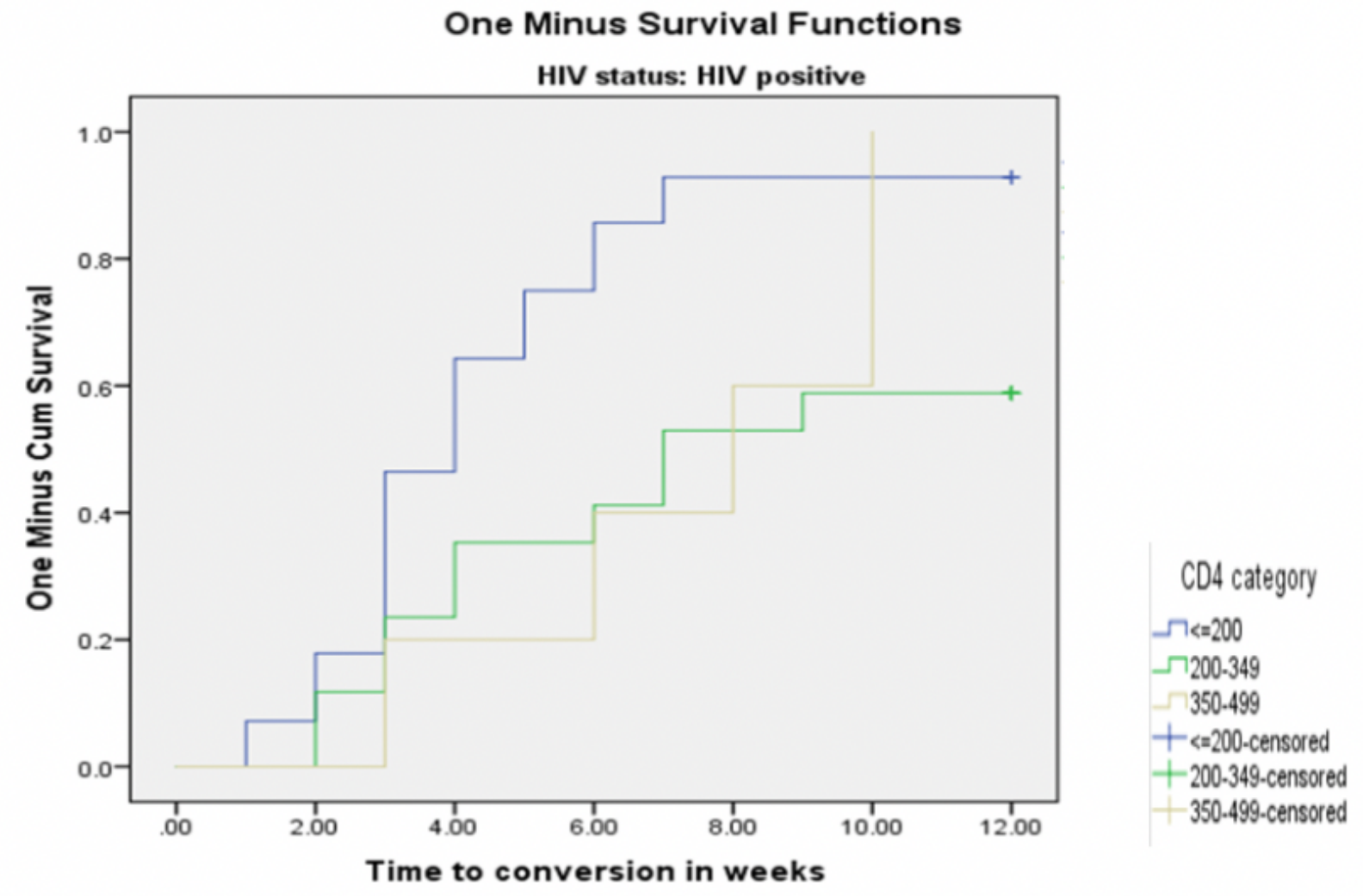

Figure 3

Smear conversion rate and time-to-conversion (weeks) by immune-suppression levels in HIV patients co-infected with MDR-TB.

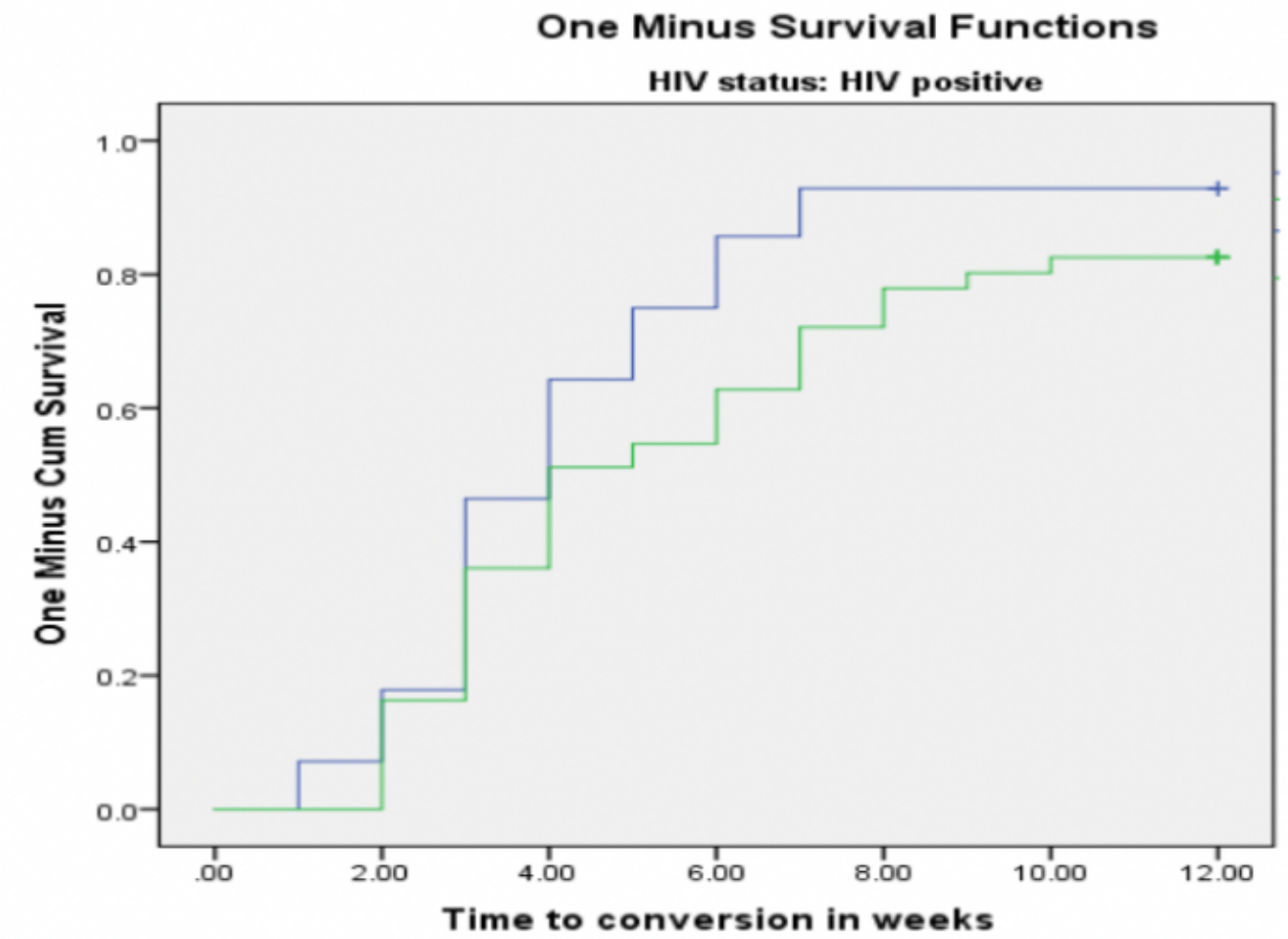

CD4 groups

$\Omega<200$ CD4 cells $/ \mathrm{mm} 3$

$\neg>=200$ cells $/ \mathrm{mm} 3$

$+<200$ CD4 cells/mm3.

censored

$>=200$ cells $/ \mathrm{mm} 3$ -

censored 


\section{Figure 4}

Smear time-to-conversion (in weeks) by levels of immune-suppressions (CD4)

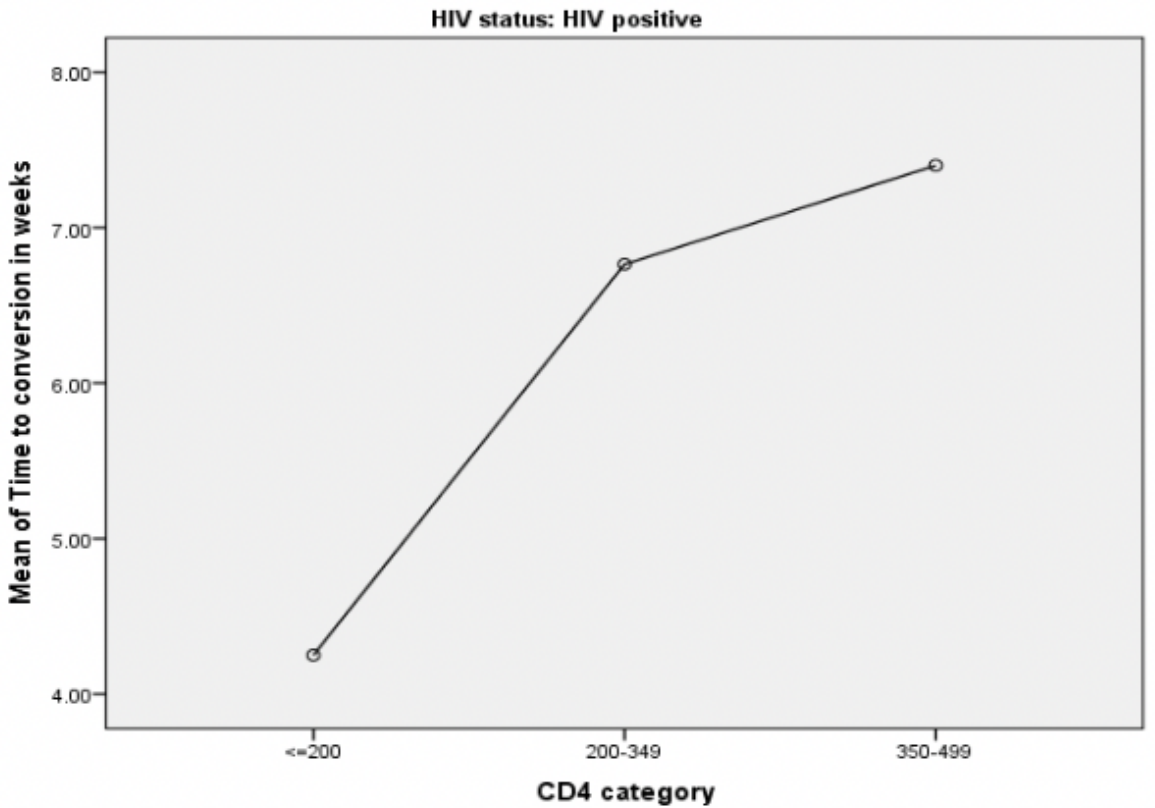

Figure 5

Distribution of time-to-conversion (in weeks) among MDR-TB patients by CD4 count categories

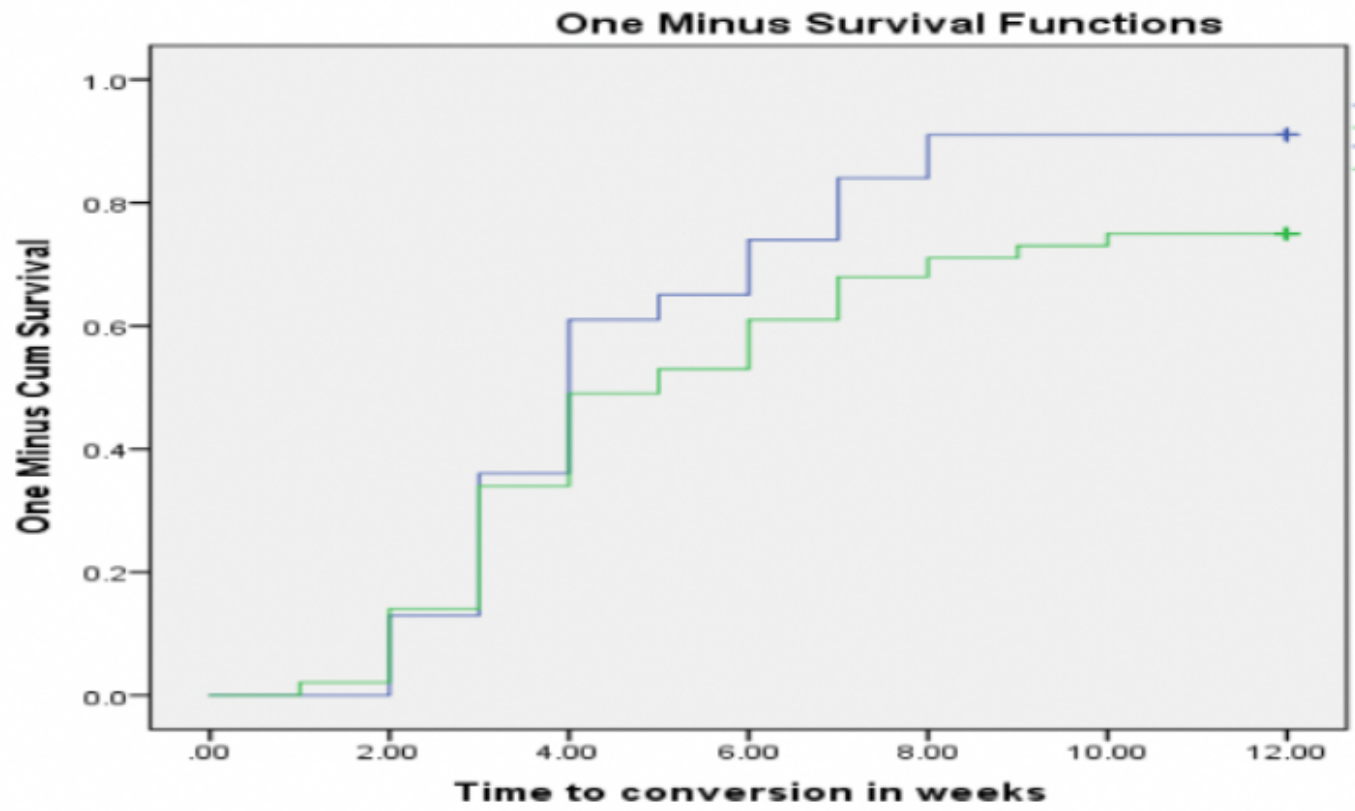

MDR status

- No

-rYes

+ No-censored

+ Yes-censored

\section{Figure 6}

MDR-TB status as determinant of smear conversion rate in TB patients $(p=0.003)$ 


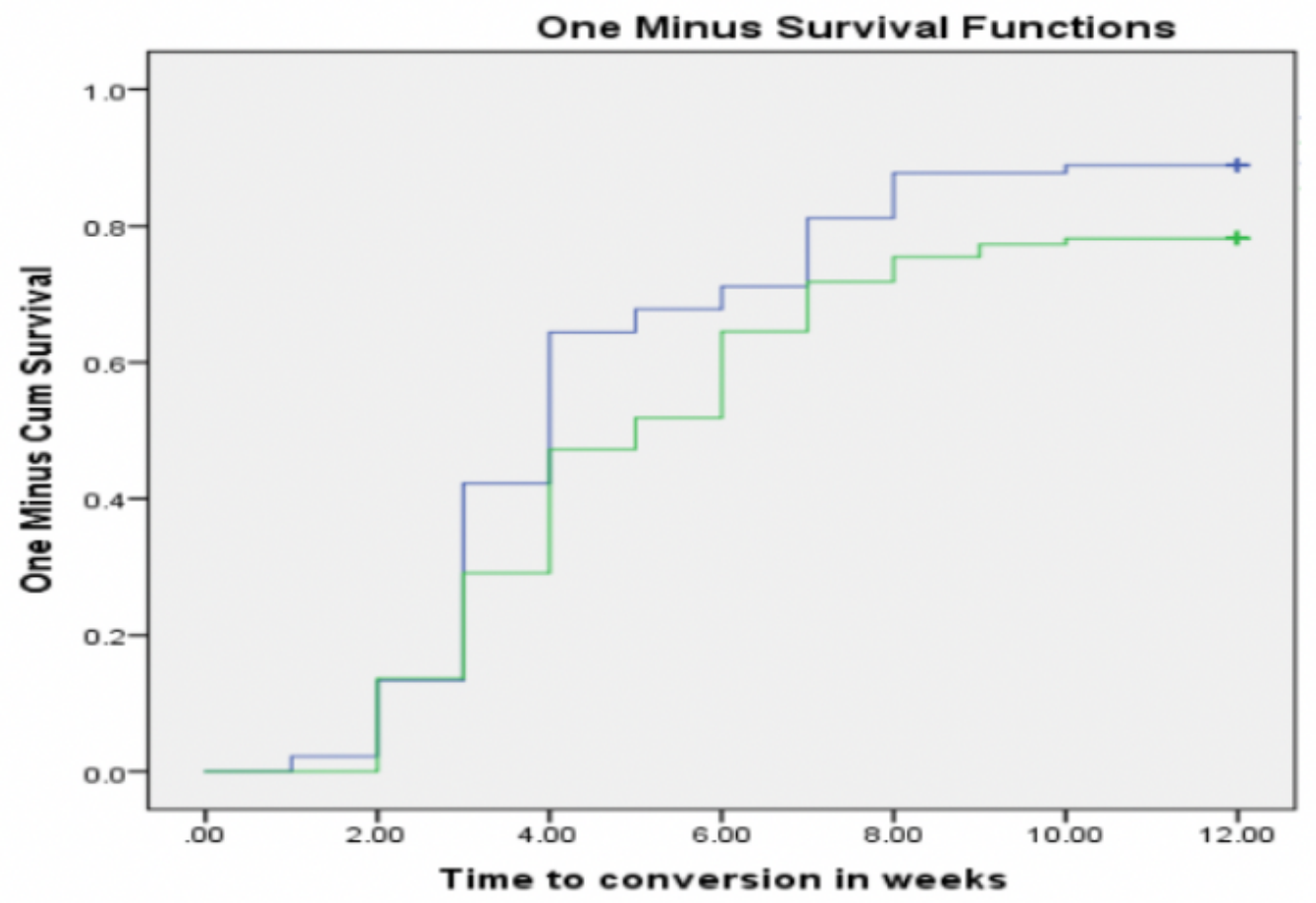

Age groups

$\neg>=35$ years

$-7<35$ years

$+>=35$ years-censored

$+<35$ years-censored

Figure 7

Age as a determinant of sputum smear conversion rate in TB patients $(p=0.045)$

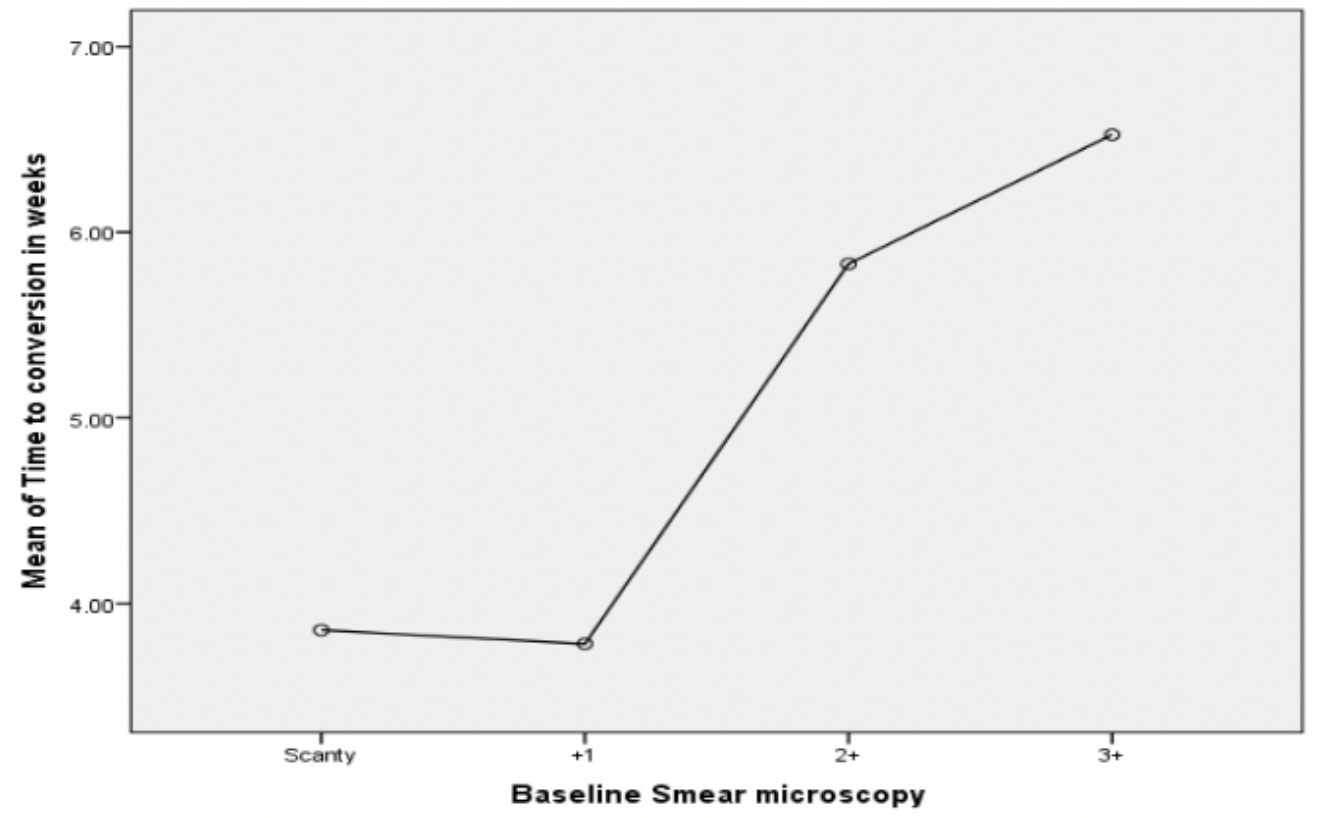

Figure 8

Time to negative conversion by baseline smear grades (in weeks) for all TB patients 


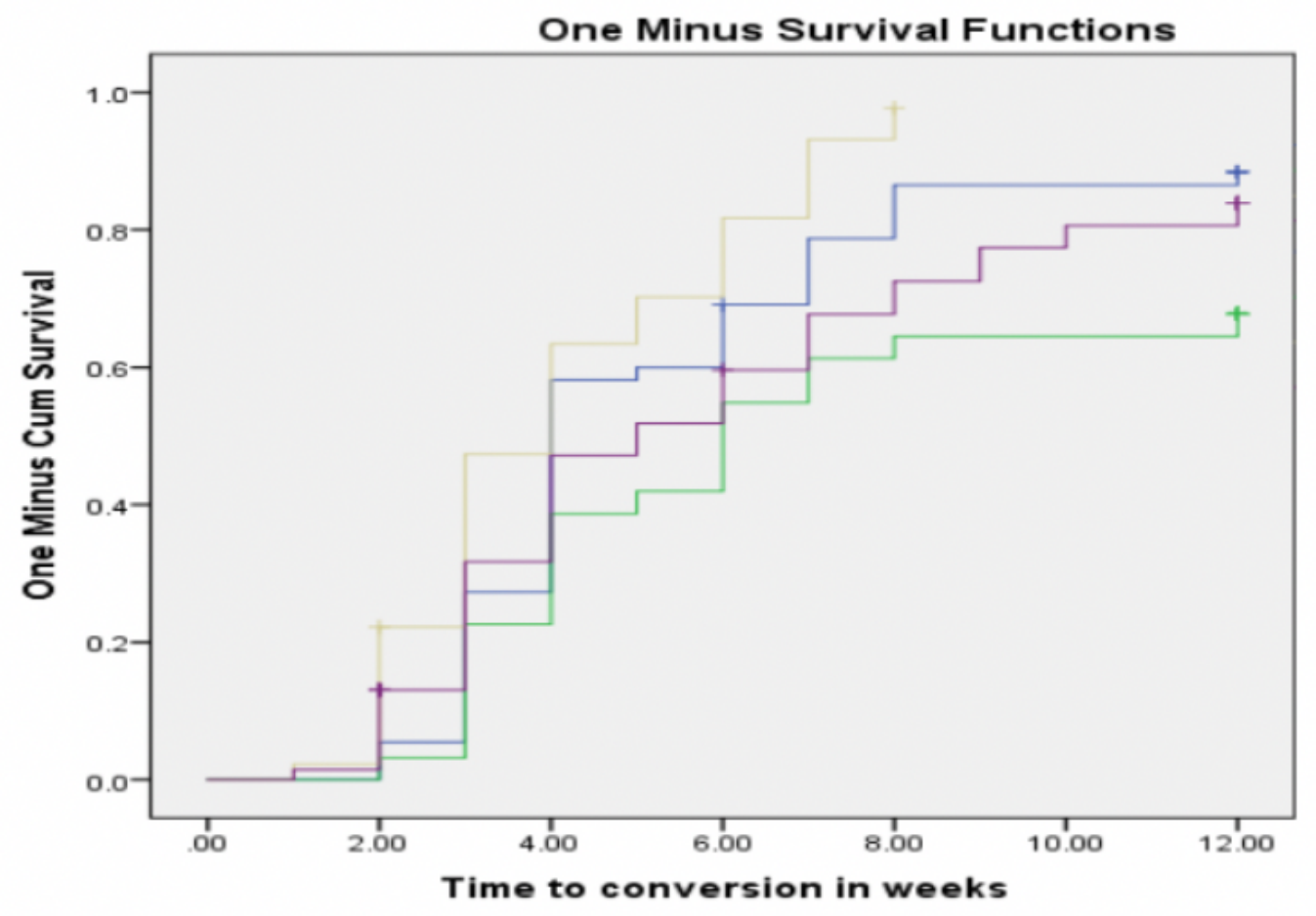

HIV and MDR status

$-\neg$ HIV(-) and MDR(-)

$-\operatorname{HIV}(-)$ and MDR(+)

HIV (+) and MDR(-)

$\rightarrow \mathrm{HIV}(+)$ and MDR(+)

+ HIV (-) and MDR(-)-

censored

+ HIV(-) and MDR(+)censored

HIV(+) and MDR(-)censored

$+\mathrm{HIV}(+)$ and MDR(+)-

censored

Figure 9

Time-to-microscopy conversion (in weeks) by HIV status from MDR-TB versus DS-TB patients

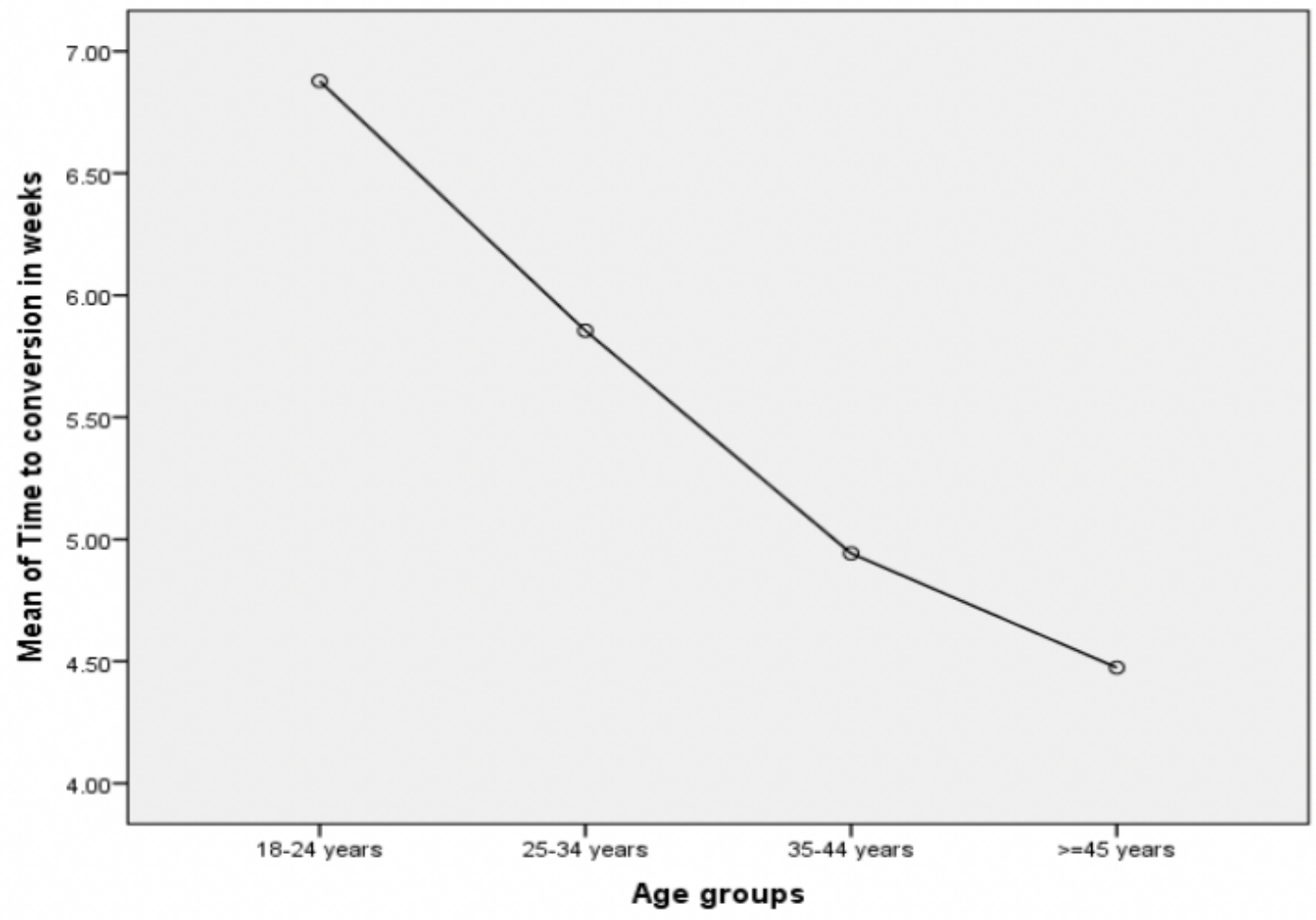

Figure 10

Time-to-conversion (in weeks) by age groups 


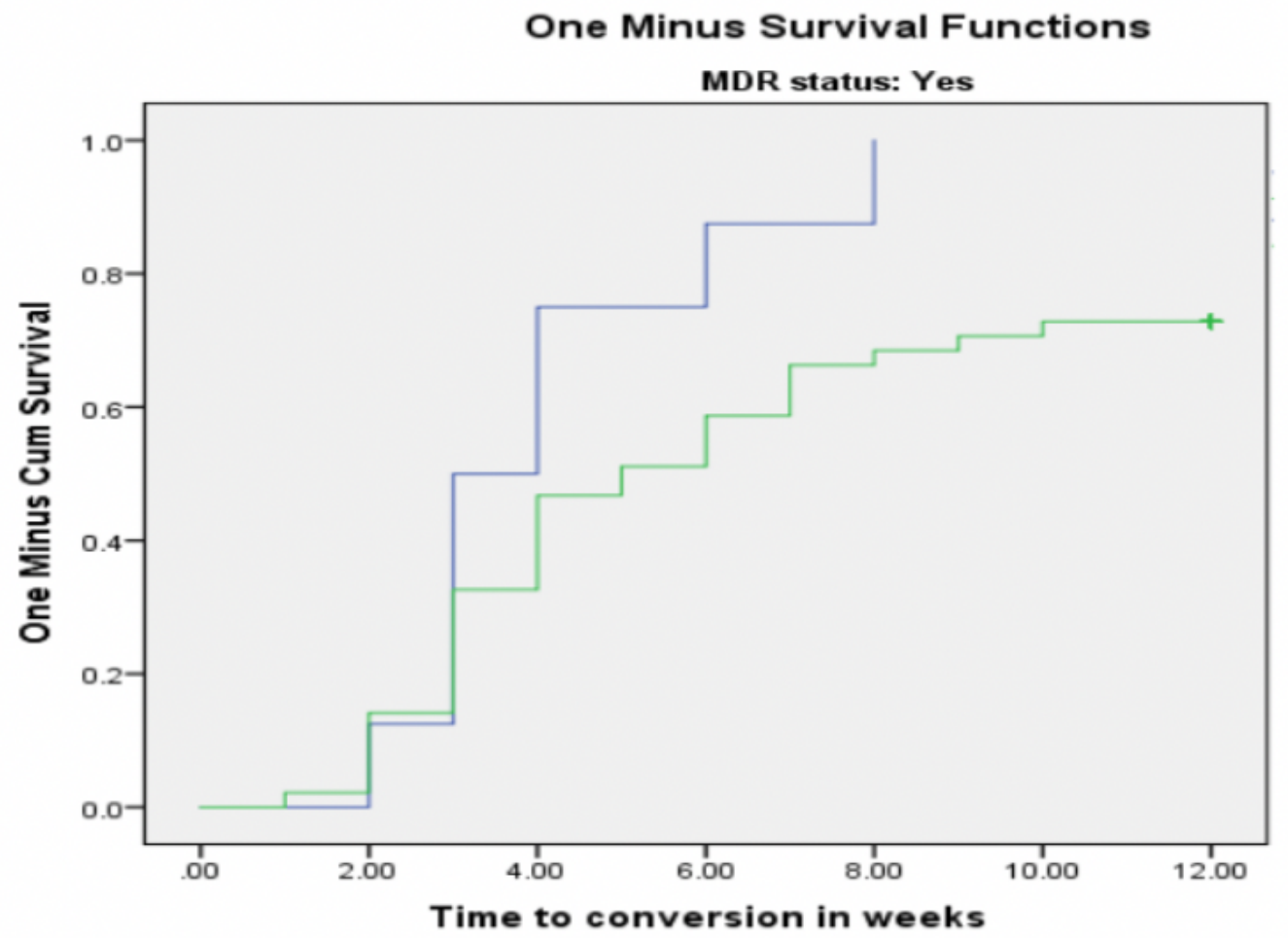

\section{Baseline smear}

-7 Scanty and +1 $-7+2$ and +3

+ Scanty and +1 -censored

++2 and +3 -censored

\section{Figure 11}

Baseline smear microscopy grade as a determinant of sputum smear conversion rate in MDR-TB patients $(p=0.014)$ 